\title{
A Matemática em uma turma de Educação Infantil: algumas situações do cotidiano
}

\author{
La Matemática en una clase Educación Infantil: algunas situaciones de lo \\ cotidiano
}

\author{
Mathematics in a class Early Childhood Education: some everyday \\ situations
}

Carla Renati Andriguetto ${ }^{1}$

Marta Cristina Cezar Pozzobon ${ }^{2}$

\begin{abstract}
Resumo
Este artigo faz um recorte nas discussões apresentadas no Mestrado em Educação que aborda os usos matemáticos de uma turma de Educação Infantil, de crianças de 4 anos, de uma escola pública do Município de Campo Novo/RS. Consideramos a seguinte questão norteadora: Em quais situações a Matemática é considerada em uma turma de educação infantil? Para tanto, realizamos uma observação participante em uma turma de vinte alunos, de quatro anos de idade durante uma semana. Com base em Ferro (2016), Barbosa (2009), Pacheco (2017) entre outros, foram realizadas análises a partir dos relatos das aulas observadas, destacando situações que envolviam a linguagem Matemática. As análises apontam que a Matemática está presente em algumas situações do cotidiano escolar, principalmente nas conversas entre as crianças, nas brincadeiras livres, na exploração do canto do Mercado e nas situações encaminhadas pela professora. Destacamos que a linguagem Matemática precisa ser considerada juntamente com as outras linguagens no cotidiano da turma de Educação Infantil, pois as crianças usam a Matemática diariamente e informalmente nas brincadeiras dentro da sala de aula, nas brincadeiras externas, na praça da escola e no lanche.
\end{abstract}

Palavras-Chave: Educação Infantil. Linguagem Matemática. Cotidiano.

\section{Resumen}

Este artículo hace un recorte en las discusiones presentadas en el Máster en Educación que aborda los usos matemáticos de una clase de Educación Infantil, de niños de 4 años, de una escuela pública del Municipio de Campo Novo / RS. Consideramos la siguiente cuestión orientadora: ¿En qué situaciones la Matemática es considerada en una clase de educación infantil? Para ello, realizamos una observación participante en una clase de veinte alumnos, de cuatro años de edad durante una semana. Con base en Ferro (2016), Barbosa (2009), Pacheco (2017) entre otros, se realizaron análisis a partir de los relatos de las clases observadas, destacando situaciones que involucra el lenguaje Matemática. Los análisis apuntan que la Matemática está presente en algunas situaciones del cotidiano escolar, principalmente en las conversaciones entre los niños, en las bromas libres, en la explotación del canto del Mercado y en las situaciones encaminadas por la profesora. En el caso de los niños, los niños usan la Matemática diariamente e informalmente en los juegos dentro del aula, en las bromas externas, en la plaza de la escuela y en la merienda.

Palabras claves: Educación Infantil; Lenguaje Matemático; Matemáticas; Observación

\footnotetext{
${ }^{1}$ Mestranda em Educação, Universidade Federal do Pampa/UNIPAMPA, Jaguarão, Rio Grande do Sul, Brasil, carla.renati@hotmail.com.

${ }^{2}$ Doutora em Educação, Docente na Universidade Federal do Pampa/UNIPAMPA, Jaguarão, Rio Grande do Sul, Brasil, marta.pozzobon@ hotmail.com.
} 


\begin{abstract}
This article makes a clipping in the discussions presented in the Master in Education that deals with the mathematical uses of a class of Early Childhood Education of 4 year olds from a public school in the Municipality of Campo Novo / RS. We consider the following guiding question: In what situations is mathematics considered in a child education class? To do so, we performed a participant observation in a class of twenty students, four years old for a week. Based on Ferro (2016), Barbosa (2009), Pacheco (2017), among others, analyzes were performed based on the reports of the classes observed, highlighting situations that involved the language Mathematics. The analyzes show that Mathematics is present in some situations of daily school life, especially in conversations among children, in free games, in the exploration of market singing and in situations addressed by the teacher. We emphasize that the language Mathematics needs to be considered together with the other languages in the daily life of the Children's Education class, since children use Mathematics daily and informally in the games inside the classroom, in the outdoor games, in the school square and in the snack.
\end{abstract}

Keywords: Child education; Mathematical Language; Mathematics; Note;

\title{
1. Introdução
}

O currículo da Educação Infantil, de acordo com as Diretrizes Curriculares Nacionais da Educação Infantil - DCNEI, envolve um “[c]onjunto de práticas que buscam articular as experiências e os saberes das crianças com os conhecimentos que fazem parte do patrimônio cultural, artístico, ambiental, científico e tecnológico, de modo a promover o desenvolvimento integral de crianças de 0 a 5 anos de idade" (BRASIL, 2009, p. 12). Diante disso, destacamos que, como alude a Base Nacional Curricular Comum - BNCC (2017), em concordância com as DCNEI (2009), as aprendizagens, o desenvolvimento e a socialização das crianças ocorrem a partir de práticas pedagógicas estruturadas pelos princípios das interações e brincadeiras.

A partir de tais ideias, destacamos a necessidade de considerar que a criança aprende pela interação e participação no mundo e no meio que vive e essas aprendizagens compartilhadas com outros sujeitos produzem outros saberes e significados para as vivências. As crianças estão inseridas e interagem nas práticas sociais e com as múltiplas linguagens, dentre elas a linguagem Matemática, que está presente no mundo, nas brincadeiras, na exploração do meio ambiente, dos objetos e das experiências (BARBOSA, 2009).

A partir dessas discussões, neste artigo, consideramos um recorte da pesquisa/intervenção que está em desenvolvimento no Mestrado Profissional em Educação, que discute os usos da Matemática em uma turma de Educação Infantil na perspectiva de respondermos a seguinte questão: Em quais situações a Matemática é considerada em uma turma de Educação Infantil? Para tanto, realizamos uma observação participante em uma turma de vinte alunos, de quatro anos de idade, durante uma semana, em uma escola pública 
do município de Campo Novo/RS ${ }^{3}$. Neste sentido, consideramos nas próximas seções algumas discussões teóricas que pautam este estudo, os caminhos metodológicos, as análises, em que abordamos as observações, as falas das crianças e na última parte, tecemos algumas considerações finais.

\section{A Educação Infantil e a Matemática}

A criança ao nascer entra em contato com o mundo, interagindo com as diferentes linguagens e com a linguagem Matemática através de objetos, grandezas, quantidades, espaço, forma, cores e tantos outros atributos, relações e transformações. Ao considerarmos a Matemática na Educação Infantil se estará trabalhando na criança o espírito investigativo, a curiosidade, a formulação de hipóteses e a resolução de problemas. Os Referenciais Curriculares Nacionais para a Educação Infantil (1998, p. 213) consideram que:

As noções matemáticas (contagem, relações quantitativas e espaciais etc.) são construídas pelas crianças a partir das experiências proporcionadas pelas interações com o meio, pelo intercâmbio com outras pessoas que possuem interesses, conhecimentos e necessidades que podem ser compartilhados. As crianças têm e podem ter várias experiências com o universo matemático e outros que lhes permitem fazer descobertas, tecer relações, organizar o pensamento, o raciocínio lógico, situar-se e localizar-se espacialmente.

O trabalho na Educação Infantil envolve as crianças, os professores e demais profissionais que trabalham no espaço da escola, com atividades pedagógicas relacionadas aos objetivos do desenvolvimento integral da criança. Cada criança traz consigo conhecimentos únicos que foram adquiridos no convívio com outros grupos sociais: família, igrejas, clubes, entre outros, e estes precisam ser incorporados juntamente com os saberes científicos ofertados pela escola. Segundo as Diretrizes Curriculares Nacionais da Educação Básica:

O conhecimento científico hoje disponível autoriza a visão de que desde o nascimento a criança busca atribuir significado a sua experiência e nesse processo volta-se para conhecer o mundo material e social, ampliando gradativamente o campo de sua curiosidade e inquietações, mediada pelas orientações, materiais, espaços e tempos que organizam as situações de aprendizagem e pelas explicações e significados a que ela tem acesso (BRASIL, 2013, p. 86).

Consideramos que a linguagem matemática faz parte das vivências das crianças e, muitas vezes, é trabalhada através de jogos, brincadeiras, dramatizações, histórias, músicas, passeios, e outros, que têm a intencionalidade de explorar, organizar, levantar hipóteses,

\footnotetext{
${ }^{3}$ Situa-se na região Noroeste do estado Rio Grande do Sul, a $450 \mathrm{~km}$ de Porto Alegre. Disponível em: http://camponovo.rs.gov.br/municipio/sobre-o-municipio/dados/. Acesso em: 20 dez. 2018.
} 
investigar e registrar as informações, para que tenham significado. As vivências partem da exploração do corpo, dos objetos e de situações que fazem parte do cotidiano da criança. Ao explorar as situações do cotidiano, a criança pode organizar o seu espaço, os objetos, resolvendo problemas, pois como aponta a DCNEI (2009), a prática pedagógica na Educação Infantil precisa considerar as experiências e os saberes das crianças, articulados com os conhecimentos do patrimônio cultural, histórico, social, dentre outros.

Cada criança tem uma história de vida com interações com outras pessoas, espaços, lugares e, também, apresentam seus próprios entendimentos acerca dessa vivência, muitas vezes, aproximam-se dos conhecimentos escolares. Aprender Matemática é um processo contínuo, no qual as crianças atribuem significados e estabelecem relações com base nas observações, experiências e ações que fazem, desde cedo, sobre elementos do seu ambiente físico e sociocultural (BRASIL, 1998). A linguagem Matemática está presente no cotidiano infantil como afirma Ferro (2016, p. 47):

\footnotetext{
Ao contar, separar, juntar, empilhar, manusear e montar objetos; comparar quantidades, tamanhos e formas; deslocar-se no espaço; indagar sobre o seu entorno e realizar tantas outras ações possíveis, a criança percebe como as pessoas fazem uso dos objetos e se comportam diante das situações diárias; aprende a agir e pensar como os seres pertencentes ao gênero humano; ela se humaniza.
}

Com essa configuração de ações no cotidiano infantil, podemos dizer que a linguagem vai além da fala e da escrita, deixando de lado a ideia que abrangeria somente esse campo, mas engloba as maneiras de pensar, de agir, de movimentar-se, expressar-se e se apresenta como uma forma de construção de sentidos do conhecimento. O trabalho na Educação Infantil, segundo a DCNEI (2009, p. 25) "[...] deve contemplar diferentes linguagens e o progressivo domínio por elas de vários gêneros e formas de expressão: gestual, verbal, plástica, dramática e musical.”

Nesta perspectiva, consideramos a importância de explorar a Matemática, para que a criança se aproprie dos conhecimentos, partindo das suas vivências, concepções, indagações e, com isso, organize diferentes formas de registro, compartilhando com os colegas e professores. Bairral e Carvalho (2012, p. 123) corroboram com tais ideias, dizendo que "O registro além de favorecer o processo de aprendizagem do aluno, favorece o processo de ensino por parte do professor, pois por meio dele é possível fazer uma análise identificando o que o aluno pensou $[\ldots]$ ”.

\section{Sobre a coleta de dados, os sujeitos e o espaço da pesquisa}


Nessa seção, consideramos a metodologia, descrevendo os materiais, como os sujeitos foram identificados e onde realizamos a observação. A turma de Educação Infantil que foi observada é um Pré-escolar, que está inserida numa escola pública do município de Campo Novo/RS. A turma é composta por 20 crianças, sendo 10 meninas e 10 meninos, todos com 4 anos de idade, oriundos da zona urbana. Dessas 20 crianças, 12 haviam frequentado a escola em anos anteriores e os demais tiveram o primeiro contato com o ambiente escolar no ano de 2018. A sala é exclusiva da turma, que ocupa o espaço à tarde, sendo uma sala de aula espaçosa e acolhedora, que foi montada juntamente com os alunos em momentos de aula, para que todos tivessem o envolvimento e a aprendizagem ao mesmo tempo. A sala contém espaços para que as crianças possam usar conforme a atividade ou simplesmente para a realização de brincadeiras livres. Através deste modo de condução da prática pedagógica, consideramos que as crianças teriam cuidado com o material e com a organização dos espaços, visto que participaram das decisões. A sala está organizada a partir de alguns espaços: da leitura, do mercado, da cabana, da informática, da exposição dos trabalhos, dos baldes com brinquedos.

Salientamos que para a preservação do anonimato das identidades das crianças, identificamos cada uma delas através das letras maiúsculas do alfabeto, independente da letra inicial de seus nomes: criança A, criança B, e assim por diante.

Realizamos a observação da rotina da turma de Educação Infantil durante 1 semana, levando em consideração a questão norteadora, e todos anotamos minuciosamente no diário de campo, para que posteriormente realizássemos as problematizações, partindo das discussões teóricas com base em Ferro (2016), Barbosa (2009), Pacheco (2017), entre outros. Foram realizadas análises a partir dos relatos das aulas observadas, destacando situações que envolviam a linguagem Matemática a partir das falas, gestos, ações ou expressões.

\section{As situações Matemáticas na turma de Educação Infantil}

As análises apontam que a Matemática está presente em algumas situações do cotidiano escolar, principalmente nas conversas entre as crianças, nas brincadeiras livres, na exploração do canto do Mercado, no lanche e nas situações encaminhadas pela professora. Com isso, trazemos a situação de uma atividade que a professora propôs para que a turma brincasse no canto do Mercado da sala e observamos o seguinte diálogo:

Criança A: "Eu quero isso”, apontando com o dedo para uma embalagem de gelatina.

Criança B: “Táa bom dá $R \$ 1,00$ ” (mas o colega não sabe identificar dinheiro). 
A criança $\mathrm{A}$ volta e entrega um brinquedo qualquer que representava o dinheiro e sai com a caixa de gelatina.

Fonte: Material da pesquisadora.

Percebemos a presença da Linguagem Matemática de maneira espontânea e informal numa brincadeira de faz de conta no canto do Mercado, indicando que ao brincar estão representando o que vivenciam e ao mesmo tempo estão produzindo conhecimento. Isso nos leva a destacar o proposto nos Parâmetros Curriculares Nacionais - PCN em relação a necessidade de estabelecer um vínculo entre a Matemática escolar e a Matemática informal.

As necessidades cotidianas fazem com que os alunos desenvolvam capacidades de natureza prática para lidar com a atividade matemática, o que lhes permite reconhecer problemas, buscar e selecionar informações, tomar decisões. Quando essa capacidade é potencializada na escola, a aprendizagem apresenta melhor resultado. (BRASIL, 1998, p. 37).

Outra situação que destacamos, ocorreu no dia de trazer o brinquedo de casa, como mostramos abaixo:

A aluna C trouxe o livro "A bruxinha atrapalhada" de Eva Furnari. Enquanto olhava os desenhos e contava sua versão da história, a criança D diz: "Eram 2 bruxas, uma má e outra boa”.

A criança E diz: "A casa da bruxa fica bem longe no meio do mato e ninguém vai a pé”. A criança F: "Só chega de vassoura e cada bruxa tem muitas vassouras."

Fonte: Material da pesquisadora.

De acordo com Barbosa (2009, p. 51) "Nada melhor que a dimensão lúdica para se defrontar com situações físicas ou matemáticas, nada como a leitura, o teatro, o desenho para aprender a ler e a escrever". Notamos que neste recorte, as crianças estão desenvolvendo a linguagem oral através da interpretação do livro, e dessa forma estão se constituindo como sujeitos, pois a linguagem é um dos eixos principais da Educação Infantil e ao compartilhar suas experiências ampliam a possibilidade da construção de mais conhecimentos. A Educação Infantil é um período caracterizado por grandes e marcantes aquisições como a formação da capacidade de fazer de conta e de representar usando diferentes linguagens (BRASIL, 2009).

$\mathrm{Na}$ brincadeira na praça da escola, as crianças resolveram brincar de esconde-esconde com os colegas de uma outra turma, em que a maioria tem 5 anos de idade.

A criança que está fechando, na brincadeira de esconde-esconde, conta até 20 , mesmo que não saiba a sequência numérica, pois ouvem os colegas da outra turma contar e contam (às vezes fora de ordem ou esquecem algum número da sequência). 
Fonte: Material da pesquisadora

Nessa situação, destacamos que muitas aprendizagens podem ocorrer, pois ao participar da experiência de "fechar e contar" para depois sair procurando os demais colegas, são desafiadas a pensar na sequência numérica, nas regras do Sistema de Numeração Decimal. Ao brincar as crianças se apropriam de linguagens e ao mesmo tempo estabelecem contato com os colegas e essas ações promovem experiências necessárias para o desenvolvimento integral. O brincar é uma atividade que as crianças se baseiam no desenvolvimento da imaginação, colocando em prática suas fantasias e conhecimentos sem a interferência de adultos. Reame destaca sobre a importância do brincar na Educação Infantil ao propor

[...] brincar com água, de pequeno construtor, de empilhar, brincar de pular corda, de esconde-esconde; brincar de roda”. São atividades que fazem parte do universo lúdico infantil, expressões que remetem às vivências ou experiências que compartilham na escola. Nesse contexto as crianças estão desenvolvendo a Linguagem Matemática. (2012, p. 120, grifos do autor).

Em outro momento, observamos as escolhas das crianças em relação ao lanche, no refeitório da escola que ofertou as seguintes opções: banana, mamão, pão com margarina e queijo e mortadela, pão puro, pão só com mortadela, ou só com queijo.

A criança G diz: "Quero os dois: pão puro e mamão".

A Criança H diz: "Quero os 3: um pão puro, banana e mamão".

A criança I diz: “quero só 1”.

Fonte: Material da pesquisadora.

Na observação, notamos que as crianças usam expressões matemáticas mesmo sem possuir o conhecimento formal escolar, pois estão inseridas em contextos de vivência em que são usadas essas expressões envolvendo quantidades, possibilidades de escolha. No momento em que as crianças solicitam seus lanches usam expressões Matemáticas aprendidas no contato com a família e com o mundo e com o decorrer do tempo podem relacionar com os conhecimentos formais da escola.

Nesse viés sobre a interação da criança com mundo, Pacheco aponta que a

A criança entra em contato com o mundo interagindo diariamente com inúmeras grandezas e objetos, produções humanas, materiais ou ideias, que podem ser lidos por meio da linguagem matemática. Quando vai para a escola, defronta-se com uma maneira de aprender que não é a mesma daquela que praticava no convívio familiar (2016, p. 71). 
Em outro momento da observação, as crianças estão brincando de casinha embaixo da cabana:

A criança J diz: "Marido quando você volta?"

A criança K responde: "Daqui uma semana".

Fonte: Material da pesquisadora.

Nesse trecho da transcrição, observamos que as crianças brincam encenando o seu cotidiano, representando as ações que vivenciam em seus contextos, demonstrando maneiras de entender o mundo a sua volta. As DCNEI (2009) trazem a necessidade de garantia da criança da Educação Infantil ter acesso as diferentes linguagens como um direito, assim como o direito à saúde, como destacamos abaixo:

A proposta pedagógica das instituições de Educação Infantil deve ter como objetivo garantir à criança acesso a processos de apropriação, renovação e articulação de conhecimentos e aprendizagens de diferentes linguagens, assim como o direito à proteção, à saúde, à liberdade, à confiança, ao respeito, à dignidade, à brincadeira, à convivência e à interação com outras crianças. (BRASIL, 2009, p. 18).

$\mathrm{Na}$ atividade com a massa de modelar, as crianças brincavam na mesa grande de madeira, como destacamos abaixo:

A criança L virou-se e me chamou: "Olha profe fiz um ninho de passarinho e tem ovinhos!" Eu olho para o ninho pequeno com ovinhos minúsculos dentro e pergunto: "Que legal!, mas quantos ovos tem aí?"

A criança L diz: “Tem 2”.

Após este episódio, outros colegas também resolveram fazer ninhos com tamanhos e quantidades variadas dentro de seus ninhos.

Fonte: Material da pesquisadora.

A BNCC (2017) diz que as experiências com conhecimentos matemáticos (contagem, ordenação, relações entre quantidades, dimensões, medidas, comparação de pesos e de comprimentos entre outros) aguçam a curiosidade e por isso a Educação Infantil precisa promover experiência para que as crianças possam observar, manipular objetos e investigar o seu entorno a fim de oportunizar que as crianças se apropriem de conhecimentos para usá-los em seu cotidiano.

\section{Algumas considerações}


Após descrevermos algumas situações de uma turma de Educação Infantil, percebemos que as crianças usam os saberes matemáticos em diferentes contextos, demonstrando que a presença da linguagem Matemática é constante nas brincadeiras, nos diálogos e no lanche, mesmo envolvendo as situações vivenciadas no dia a dia. Destacamos que os usos matemáticos das crianças mostram a importância de tais saberes para as práticas em outros contextos, nas suas relações fora dos muros da escola.

A linguagem desenvolvida pela criança nessa faixa etária através das brincadeiras, jogos e diálogos ente tantas outras ações possui uma finalidade que é estabelecer um sistema de conceitos que possa ser usado como forma de comunicação dentro da cultura humana. Para contribuir com essas ideias, destacamos o que diz Ferro (2016, p. 30) ao se referir que

[...] a principal finalidade da linguagem é estabelecer um sistema convencional que perpetue o pensamento da humanidade por meio dos gestos e desenhos, da fala e escrita, controlando quantidades, criando símbolos, termos e conceitos que possam ser utilizados para a consolidação da cultura humana e para a regulação do comportamento do homem, fazendo dele um ser detentor do mais alto nível de abstrações.

$\mathrm{O}$ acesso às diferentes linguagens possibilita que os sujeitos participem do seu mundo, apropriando-se dos objetos, dos saberes e dos códigos. As crianças vivenciam as linguagens do cotidiano no contexto escolar, usando muitas expressões e saberes que se assemelham as suas formas de vida. Isso pode ser percebido nas brincadeiras, no faz de conta, em que usam as ideias de quantidade, de contagem, do valor do dinheiro, das escolhas do lanche.

Portanto, ressaltamos que a Matemática é usada em diferentes situações, demonstrando as vivências com tais saberes, que se constituíram através do processo de interação com outras pessoas. Conforme observamos, as situações matemáticas “[...] são manifestações de competências, de aprendizagem advindas de processos informais, da relação individual e cooperativa [...]" (BRASIL, 1998, p. 13).

\section{Referências}

BAIRRAL, Marcelo Almeida. CARVALHO, Mercedes (orgs). Matemática e Educação Infantil: investigações e possibilidades de práticas pedagógicas. Petrópolis, RJ: Vozes, 2012.

BARBOSA, Maria Carmen Silveira (consultora). Projeto de cooperação técnica MEC e Ufrgs para Construção de orientações curriculares para a educação Infantil -Práticas cotidianas na Educação Infantil- bases para a reflexão sobre as orientações curriculares UFRGS, 2009.

BRASIL. Diretrizes Curriculares Nacionais da Educação Básica. Ministério da Educação e do Desporto, Secretaria de Educação Fundamental. Brasília: MEC/SEF, 2013. 
BRASIL, Ministério da Educação. Secretaria de Educação Básica. Diretrizes Curriculares Nacionais para a Educação Infantil. Brasília: MEC, SEB, 2009.

BRASL. Ministério da Educação e do Desporto. Secretaria de Educação Fundamental. Referencial Curricular Nacional para a Educação Infantil. Brasília: MEC/SEF, 1998.

BRASIL. Ministério da Educação. Base Nacional Comum Curricular - BNCC. Brasília, DF, 2017.

BRASIL. Secretaria de Educação Fundamental. Parâmetros Curriculares Nacionais: Matemática / Secretaria de Educação Fundamental. Brasília: MEC / SEF, 1998

FERRO, Lussuede Luciana de Sousa. A criança da Educação Infantil e a Linguagem Matemática: relações interdependentes no processo de ensino e aprendizagem. $163 \mathrm{f}$. Dissertação (Mestrado em Educação) - Universidade Estadual de Maringá. Orientadora: Sílvia Pereira Gonzaga de Moraes. Maringá, 2016.

PACHECO, Ana Luisa Viana. Matemática na creche? Uma reflexão sobre as práticas pedagógicas em um centro municipal de Educação Infantil em Contagem. 164 f. Dissertação (Mestrado) - Universidade Federal de Minas Gerais. Orientadora: Maria Inês Mafra Goulart. Belo Horizonte, 2017.

REAME, Eliane et al. Matemática no dia a dia da Educação Infantil: rodas, cantos, brincadeiras e histórias. São Paulo: Livraria Saraiva, 2012. 